\title{
Triatominae species of Suriname (Heteroptera: Reduviidae) and their role as vectors of Chagas disease
}

\author{
Hélène Hiwat/+ \\ Department of Entomology, Bureau of Public Health, Paramaribo, Suriname
}

\begin{abstract}
Nine species of Triatominae, representing three tribes and five genera, are currently known in Suriname. An annotated list of the species based on the collections of the Bureau of Public Health (Suriname), the National Zoological Collection Suriname and the National History Museum Leiden (the Netherlands) is provided. Additionally, the results of several years of opportunistic collection in two domestic environments are presented. The most common species are Rhodnius pictipes Stål, 1972, Rhodnius robustus Larrouse, 1972 and Panstrongylus geniculatus (Latreille, 1811). The significance of the species as vectors of Chagas disease in Suriname is discussed.
\end{abstract}

Key words: Heteroptera - Reduviidae - Triatominae - Chagas disease - Suriname

The surveillance and control of Chagas disease (American trypanosomiasis) is given high priority by most Latin American countries. However, the disease is not well known in the Guianas (Guyana, Suriname and French Guiana) and research efforts are limited. Furthermore, active surveillance and control are in initial phases or have yet to be developed (Luquetti \& Schofield 2004, PAHO 2009, Salamanca-Dejour et al. 2012). Relatively few cases have been reported in these countries. In Suriname, three acute cases of Chagas disease were reported: one in 2001 (Oostburg et al. 2003) and the other two in 2012 and 2013 (S Vreden, unpublished observations). Based on the patients' lack of international travel history, these cases were considered autochthonous cases; one of them was a male infant who had not been out of the capital, Paramaribo. Two chronic cases had been detected serologically some 20 years before (Rawlings et al. 2001) and recent serological surveillance of the blood bank revealed five new chronic cases (S Vreden, unpublished observations). These cases were all considered autochthonous cases.

Haematophagous Triatominae, vectors of Chagas disease, are also relatively unknown in the Guianas and investigations into their diversity and distribution in the three countries are scarce (Lent \& Wygodzinsky 1979, Bérenger et al. 2009). Lent and Wygodzinsky (1979) mentioned the occurrence of Triatoma maculata (Erichson, 1848), Eratyrus mucronatus Stål, 1859, Panstrongylus geniculatus (Latreille, 1811), Panstrongylus lignarius (Walker, 1873), Rhodnius pictipes Stål, 1872, Rhodnius prolixus Stål, 1859 and Microtriatoma trinidadensis (Lent, 1951) in Suriname. This was partially based on an investigation by Lent (1943); although in Lent's study the presence of Triatoma rubrofasciata (De Geer, 1773) was recognised as well. Abad-Franch and

doi: $10.1590 / 0074-0276130408$

+ Corresponding author: helenehiwat@gmail.com

Received 20 August 2013

Accepted 2 May 2014
Monteiro (2007) considered the Triatominae of the wider "humid Guyana" (which includes Guyana, Suriname and French Guiana) and for this region added Rhodnius robustus Larrousse, 1927 (genotype IV), Rhodnius amazonicus Almeida, Santos \& Sposina, 1973, Rhodnius paraensis Sherlock, Guitton \& Miles, 1977 and Panstrongylus rufotuberculatus (Champion, 1899) to the list, while speculating about the presence of $R$. prolixus Stål, 1859, Triatoma dimidiata (Latreille, 1811), Triatoma nigromaculata (Stål, 1859) and Cavernicola pilosa Barber, 1937. T. rubrofasciata, as in Lent and Wygodzinsky (1979), is not included in their species list for this region.

Over the last decade, an increased interest in Chagas disease and its vectors has developed in Suriname, leading to serological surveys and collections of Triatominae. The results of these Triatominae collections are reported here. This information, combined with an assessment of the available historical data on the subject, results in a comprehensive Triatominae species list for Suriname. The vector importance of the species is also discussed.

\section{MATERIALS AND METHODS}

An overview of the Triatominae species of Suriname was generated based on the specimens and collection data available at the collections of the Bureau of Public Health in Suriname (BOG) and the National Zoological Collection of Suriname (NZCS), Anton de Kom University, on the information provided by the Natural History Museum of Leiden (NHML) (the Netherlands) and on a literature review. Suriname obtained independence from the Netherlands in 1975. As flora and fauna specimens collected during the colonial years were often transported to the Netherlands and stored at the NHML, the information on the Triatominae collection of this museum was included in this study.

The Republic of Suriname is situated on the Caribbean coast between Guyana and French Guiana, north of Brazil. The country is divided into 10 districts (Fig. 1) that cover three major ecological landscapes: the northern coastal area, the southern forested highlands and the savannah belt in between. The coastal area is mainly lowland with swamps and mangroves, but also has shell 


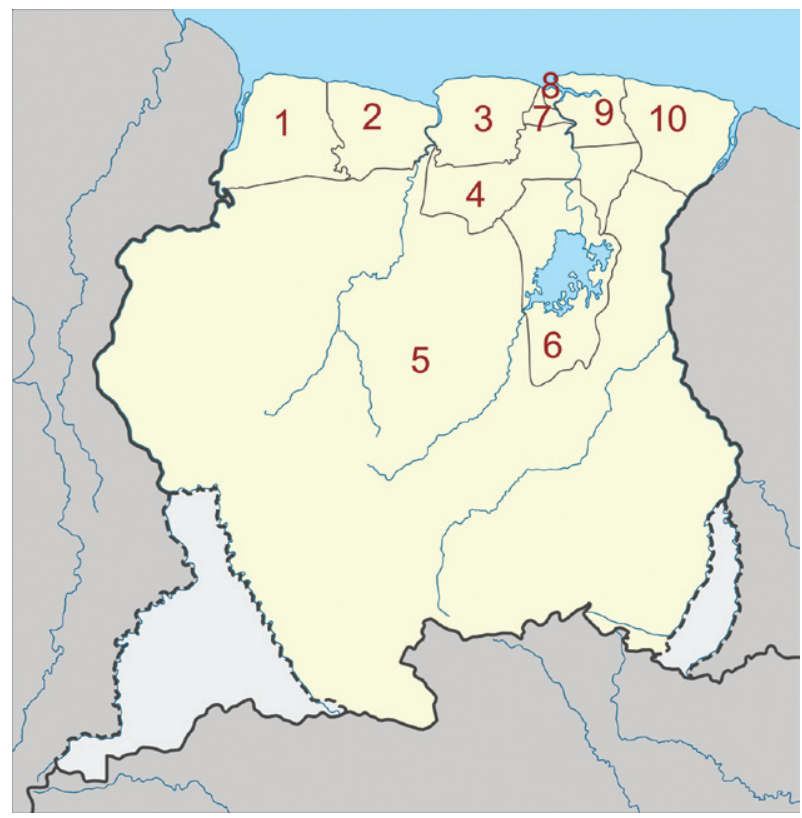

Fig. 1: map of Suriname showing the 10 districts: 1: Nickerie; 2: Coronie; 3: Saramacca; 4: Para; 5: Sipaliwini; 6: Brokopondo; 7: Wanica; 8: Paramaribo (capital); 9: Commewijne; 10: Marowijne.

ridges; it is the most populated part of the country and almost all national agriculture is performed that region. The highlands in the interior are almost completely covered with tropical rainforest; however, deforestation, especially due to gold mining, is increasing significantly. This area has some inselbergs or tepuis and small savannah areas along the south-southeastern border. The savannah belt stretches from east to west and separates the coastal lowlands from the interior highlands (Fig. 2).

Approximately $90 \%$ of the country is uninhabited. Of the approximately 500,000 inhabitants, $70 \%$ are concentrated in and around Paramaribo. Another 25\% live in small towns along the roads and rivers of the coastal area. The remaining $5 \%$ of the population live in small villages in the savannah belt and interior, mostly along the Marowijne, Suriname and Saramacca rivers. In addition, there is a growing population of Brazilian mineral prospectors (garimpeiros; estimated to be at least 15,000 people) involved in the rapidly growing, small-scale gold mining activities in the interior.

Suriname's tropical rainforest climate, with an average temperature of $27^{\circ} \mathrm{C}$ and an average humidity of approximately $80 \%$, is advantageous for a number of Triatominae species.

Active collection of Triatominae was performed by the author as part of an NZCS project in 2002. Field surveys were conducted in Kwamalasamutu (south Suriname, on the border with Brazil) and in Djoemoe and Nieuw-Aurora (central Suriname, along Suriname River) using livebait traps [according to Abad-Franch et al. (2000)] and by the dissection of palm trees. Following this project and as a result of mutual interest, the author and two colleagues started opportunistic collection of the Triatominae encountered in and around their residences.

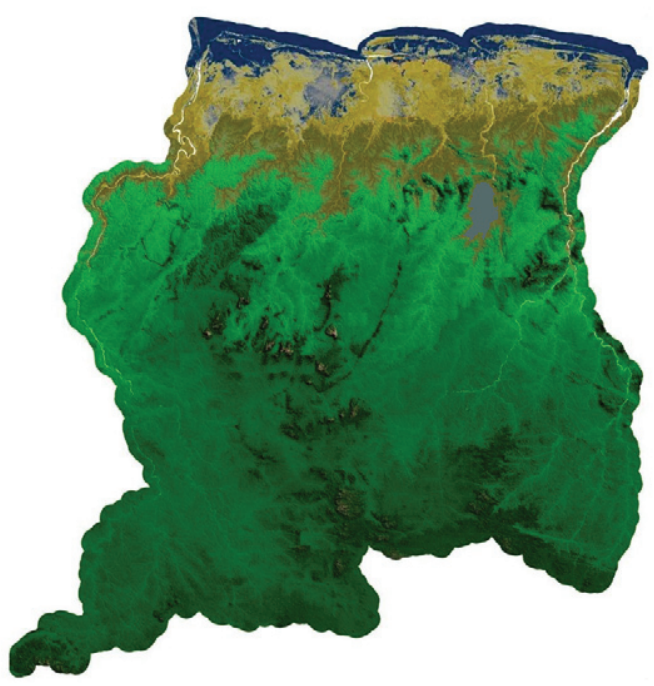

Fig. 2: satellite image of Suriname showing the coastal area (yellow), the savannah belt (light brown) and the forested highlands (green).

\section{RESULTS}

The current combined amount of Triatominae specimens in the three collections (NHML, NZCS and BOG) is 429 and represents seven species (Table I): $62.5 \% R$. pictipes, $20.3 \%$ P. geniculatus and $9.6 \%$ R. robustus. The specimens of the NHML were collected between 18871965. The NZCS holds specimens collected from 1998 and the BOG collections started in 2005. A vast majority of the NZCS and BOG specimens conserved since 2002 originate from the opportunistic collection by the author and colleagues from two of the three residences. Table II provides an overview of these Triatominae, which were found at a residence in rural surroundings in the district of Wanica between 2002-2005 and at a residence, also in rural surroundings, in the district of Saramacca between 2002-2012. At the Wanica residence, a total amount of 58 Triatominae specimens were collected within the four years (R. pictipes, P. geniculatus, P. rufotuberculatus, $P$. lignarius), mostly attracted to a light on the balcony. The Saramacca residence yielded 133 Triatominae in 11 years ( $R$. pictipes, $R$. robustus, $P$. geniculatus). Most of these specimens were collected indoors. All these specimens were included in either the NZCS or the BOG insect collections (Table I).

The active collection of Triatominae in 2002 yielded very little. Collection with live-bait traps was unsuccessful. The dissection of palm trees resulted in one adult $R$. pictipes from Kwamalasamutu and one $R$. robustus nymph from Nieuw Aurora, both from maripa palm (Attalea maripa). The $R$. pictipes adult was found near an opossum (Didelphidae) nest, where it most likely found its blood meals. The $R$. robustus nymph was reared to adulthood before incorporation into the collection. These specimens were included in the NZCS collection (Table I).

Confirmed species - Six of the seven species of Triatominae from Suriname currently represented in the historical collection of the NHML were also found since 
TABLE I

Triatominae species of Suriname

\begin{tabular}{|c|c|c|c|c|}
\hline \multirow[b]{2}{*}{ Species } & \multicolumn{4}{|c|}{$\begin{array}{c}\text { Specimens } \\
\mathrm{n}(\%)\end{array}$} \\
\hline & NHML & BOG & NZCS & Total \\
\hline Eratyrus mисronatus & $12(7.9)$ & $0(0)$ & $1(0.6)$ & $13(3)$ \\
\hline Microtriato trinidadensis ${ }^{a}$ & $0(0)$ & $0(0)$ & $0(0)$ & $0(0)$ \\
\hline Panstrongylus geniculatus & 47 (30.9) & $0(0)$ & $40(25.8)$ & $87(20.3)$ \\
\hline Panstrongylus lignarius & $2(1.3)$ & $0(0)$ & $1(0.6)$ & $3(0.7)$ \\
\hline Panstrongylus mitarakaensis ${ }^{b}$ & $0(0)$ & $0(0)$ & $0(0)$ & $0(0)$ \\
\hline Panstrongylus rufotuberculatus & $5(3.3)$ & $0(0)$ & $11(7.1)$ & $16(3.7)$ \\
\hline Rhodnius pictipes & $73(48)$ & $103(84.4)$ & $92(59.4)$ & $268(62.5)$ \\
\hline Rhodnius robustus & $12(7.9)$ & $19(15.6)$ & $10(6.5)$ & $41(9.6)$ \\
\hline Triatoma maculata & $1(0.7)$ & $0(0)$ & $0(0)$ & $1(0.2)$ \\
\hline
\end{tabular}

$a$ : Lent and Wygodzinsky (1979) refer to a M. trinidadensis specimen originating from Suriname and stored at the National History Museum at Leiden (NHML) (the Netherlands). This specimen no longer exists; $b$ : the single known specimen of $P$. mitarakaensis is in France (French Guiana) (Bérenger \& Blanchet 2007). Data on number of specimens collected and their relative abundance (\%) in the collections (until August 2013) from the NHML, Bureau of Public Health in Suriname (BOG) and the National Zoological Collection of Suriname (NZCS).

1998, which confirms their presence in the country. $T$. maculata, collected in colonial times, was not found recently. According to Lent and Wygodzinsky (1979), a specimen of $M$. trinidadensis, collected in Paramaribo, used to be present at the NHML. However, this is no longer the case and the species was not found in the country during the recent collections. The Triatominae species known to be present in Suriname are E. mucronatus, $P$. geniculatus, Panstrongylus mitarakaensis, $P$. rufotuberculatus, $P$. lignarius, $R$. pictipes and $R$. robustus.

The presence of $R$. robustus, $P$. rufotuberculatus and $P$. mitarakaensis in the country was not reported previously. P. mitarakaensis (Bérenger \& Blanchet 2007) is a recently discovered species. It was obtained from a locality at the Mitaraka mountain range, situated between the Litani River and Marowijne River, which is part of the southern border range between Suriname and French Guiana.

Species in need of confirmation - The presence of four species requires confirmation. $M$. trinidadensis was not collected recently. Nonetheless, its presence in Suriname is entirely possible because a specimen was recently found in French Guiana, less than $200 \mathrm{~km}$ from Suriname (Bérenger et al. 2009). T. maculata was collected in colonial times, but has not been seen found since. A similar situation occurred in French Guiana (Bérenger et al. 2009), where records of its presence (Carcavallo et al. 1999) could not be confirmed. The species shows an inclination for occurrences in peridomestic or domestic environments (Lent \& Wygodzinsky 1979, Luitgards-Moura et al. 2005, Reyes-Lugo et al. 2011). The fact that the species has not been found since its first recordings allows for speculation that it may no longer exist in the country or that previous identifications may have been incorrect. The presence of T. rubrofasciata in Suriname was mentioned by Lent (1943) based on a study by Stoll in 1788 .
The distribution range of $T$. rubrofasciata extends from Florida and Caribbean islands to the northern and eastern Atlantic coasts of South America (Carcavallo et al. 1999) and the species is reported from port cities throughout its range (Lent \& Wygodzinsky 1979, Braga et al. 1998). T. rubrofasciata is known for its transmission of Trypanosoma conorhini among rats (Braga et al. 1998). Its presence in Suriname would be consistent with its known distribution and is possible, though the species is unlikely to be abundant. Some specimens are known from Cayenne (French Guiana), collected in 1975, but the species has not been collected since (Bérenger et al. 2009).

The previous inclusion of Suriname in the distribution area of $R$. prolixus (Lent \& Wygodzinsky 1979) is suspected due to misidentified $R$. robustus specimens. $R$. robustus is rather common and the two species are notoriously difficult to separate morphologically (Miles et al. 1981, Harry 1993a, b, Monteiro et al. 2003). The distribution range of $R$. prolixus may in fact exclude the Guiana Shield (Monteiro et al. 2003, Pavan \& Monteiro 2007), which will make its presence in the country even more unlikely.

Species likely to be present - Some triatomine species known from bordering regions or due to their currently known distribution range are likely to be present in Suriname as well. C. pilosa, $R$. amazonicus and $R$. paraensis were collected from northern Brazil (state of Pará) and French Guiana (Carcavallo et al. 1999, Bérenger et al. 2009) and are likely to be present in the country.

\section{DISCUSSION}

Of the seven confirmed Triatominae species from $\mathrm{Su}-$ riname, only three can be considered relatively abundant: $P$. geniculatus, $R$. pictipes and $R$. robustus (Table I). All three species are likely to contribute directly or indirectly 
TABLE II

Number of triatomine specimens found in a residence in Saramacca (S) between 2002-2012 and in a residence in Wanica (W) between 2002-2005 as a result of opportunistic collection

\begin{tabular}{|c|c|c|c|c|c|c|c|c|c|c|}
\hline & \multicolumn{2}{|c|}{$\begin{array}{l}\text { Rhodnius } \\
\text { pictipes }\end{array}$} & \multicolumn{2}{|c|}{$\begin{array}{l}\text { Rhodnius } \\
\text { robustus }\end{array}$} & \multicolumn{2}{|c|}{$\begin{array}{l}\text { Panstrongylus } \\
\text { geniculatus }\end{array}$} & \multicolumn{2}{|c|}{$\begin{array}{l}\text { Panstrongylus } \\
\text { rufotuberculatus }\end{array}$} & \multicolumn{2}{|c|}{$\begin{array}{c}\text { Panstrongylus } \\
\text { lignarius }\end{array}$} \\
\hline & $\mathrm{S}$ & W & $\mathrm{S}$ & W & S & W & $\mathrm{S}$ & W & $\mathrm{S}$ & W \\
\hline 2002 & 2 & 9 & 1 & 0 & 1 & 9 & 0 & 0 & 0 & 0 \\
\hline 2003 & 3 & 19 & 6 & 0 & 0 & 2 & 0 & 5 & 0 & 0 \\
\hline 2004 & 7 & 5 & 4 & 0 & 0 & 1 & 0 & 3 & 0 & 1 \\
\hline 2005 & 3 & 2 & 1 & 0 & 0 & 1 & 0 & 1 & 0 & 0 \\
\hline 2006 & 4 & - & 1 & - & 0 & - & 0 & - & 0 & - \\
\hline 2007 & 10 & - & 2 & - & 0 & - & 0 & - & 0 & - \\
\hline 2008 & 18 & - & 0 & - & 0 & - & 0 & - & 0 & - \\
\hline 2009 & 21 & - & 10 & - & 0 & - & 0 & - & 0 & - \\
\hline 2010 & 24 & - & 2 & - & 0 & - & 0 & - & 0 & - \\
\hline 2011 & 2 & - & 0 & - & 0 & - & 0 & - & 0 & - \\
\hline 2012 & 8 & - & 3 & - & 0 & - & 0 & - & 0 & - \\
\hline Total & 102 & 35 & 30 & 0 & 1 & 13 & 0 & 9 & 0 & 1 \\
\hline $\begin{array}{l}\text { Total/species } \\
\text { n (\%) }\end{array}$ & \multicolumn{2}{|c|}{137 (71.7) } & \multicolumn{2}{|c|}{$30(15.7)$} & \multicolumn{2}{|c|}{$14(7.3)$} & \multicolumn{2}{|c|}{$9(4.8)$} & \multicolumn{2}{|c|}{$1(0.5)$} \\
\hline
\end{tabular}

[via contamination of food sources (Nóbrega et al. 2009)] to the transmission of Trypanosoma cruzi to the human population (Lent \& Wydgonzinsky 1979, Barrett 1991, Oostburg et al. 2003, Gurgel-Gonçalves et al. 2012). The collection data from the NZCS and BOG reveal that, although there is no domestic colonisation, it is common for the adults of these three species to enter residences, which is as likely in the forest as it is in rural areas and in the capital ( $R$. robustus excluded because it was not collected in the capital). It is thought that, depending on the peridomestic vegetation characteristics, these species, especially $R$. robustus and $R$. pictipes, may even establish large colonies near houses, surviving by opportunistic feeding on mammals (Abad-Franch et al. 2005).

$R$. pictipes is the most common species in all three insect collections and was most often encountered during the opportunistic collections in and around the residences in Wanica and Saramacca (Table II) $(71.7 \%$ of the total). $P$. geniculatus was the second most frequently encountered species in the NHML and NZCS collections, but is absent from the BOG collection. Its potential as a Chagas disease vector is thought to be significant due to its broad ecological range and its frequent occurrence in peridomestic habitats and domiciliary invasion by adults (Gurgel-Gonçalves et al. 2012). P. geniculatus was the second most common species collected from the Wanica residence, but was encountered only once at the Saramacca residence. In contrast, the Saramacca residence had many R. robustus specimens, whereas no specimens of this species were encountered in or around the Wanica residence (Table II). Considering that both residences had an abundance of nearby vegetation (including palm trees) and a number of dogs and other domestic animals, which provide a blood source around the house, it is difficult to explain these differences. Environmental issues, such as vegetation diversity and characteristics (Abad-Franch et al. 2005, 2010), the (resulting) diversity in the availability of wild blood sources and the availability of light sources as attractants (Castro et al. 2010) may have played a role.

In the forests of the interior, the Maroon, Amerindian and garimpeiro populations often live in thatchroofed or zinc-roofed huts or houses with wooden walls. The relatively poor housing conditions, combined with the increased use of electric lights as an attractant for the vectors (Castro et al. 2010), provide opportunity for the accidental entry of Triatominae into houses. Factors that may further promote the entry of Triatominae into houses include land use changes (e.g., deforestation for gold mining) (Barrett 1991, Abad-Franch et al. 2005) and the custom of keeping hunting dogs and chickens near sleeping quarters.

Taking into account that the common Triatominae species found in Suriname are palm-inhabiting species, Chagas disease can be considered an occupational risk for thatch and palm fruit harvesters. In addition, palm fruit consumers can be considered at risk for oral transmission (Roque et al. 2008, Nóbrega et al. 2009). Beverages made from the fruit of Euterpe luminosa (açai) are commercially available throughout the country.

T. cruzi transmission among wild mammals includes opossum and armadillo (Roque et al. 2008). Opossums (Didelphis spp) are common in all eco-habitats in Suriname and bring the sylvatic cycle to domestic environments, thus adding to the transmission risk. Armadillo (Dasypodinae) and a number of rodents (especially Dasyproctidae), also considered part of the T. cruzi wild reservoir 
(Solís-Franco et al. 1997, Roque et al. 2008), are regularly included in the diet of people living in the interior of the country, which results in the risk of oral transmission.

The number of Triatominae specimens collected from the two rural residences each year is surprisingly high [up to 31 specimens in one year (2009) to the Saramacca residence] (Table II). Both residences are near high vegetation that includes palm trees and have some domestic animals (especially dogs) living outside the house. This is a common situation in the coastal rural areas. The risk of triatomine-to-person contact appears to be considerable in such environments and needs to be studied further.

The residences in Paramaribo are mostly well-built, one or two-story brick homes with small trees and palms in the surrounding yards and sometimes air-conditioning. Entry into houses by Triatominae appears to be a bit less common than in rural areas, though it is certainly not rare and may have been the source of the first case of acute chagasic cardiopathy in Suriname (Oostburg et al. 2003). The patient, living in a suburban residential area of Paramaribo, had adult P. geniculatus in his yard.

The actual risk of $T$. cruzi transmission, of course, depends largely on the infection rate of the vectors. Unfortunately, this information is not yet available for Suriname for any of the species found in the country. In comparison, a study in the Brazilian Amazon revealed an infection rate for $R$. pictipes of $65 \%$ (Valente et al. 2009). Determining the infection rate for the three most common species in the country will be one of the priorities of future studies and the determination of the seroprevalence of $T$. cruzi infection among the population of Suriname is a priority as well. Studies in Guyana and French Guiana indicate an overall T. cruzi seroprevalence of $0.5 \%$ for these countries (Aznar et al. 2004, PAHO 2009). In contrast, information on the seroprevalence of $T$. cruzi in the animal reservoir of Suriname does not exist. Studies on this subject will need to be developed and executed. The annotated list of Surinamese Triatominae is given below.

Bolboderini Usinger, 1944, M. trinidadensis (Lent, 1951) - The inclusion of Suriname in the distribution range of $M$. trinidadensis was based on a specimen collected in Paramaribo and conserved at the NHML (Lent \& Wygodzinsky 1979). No other reports of $M$. trinidadensis collection in Suriname are known. Unfortunately, the one specimen at the NHML no longer exists. The species is known from bromeliads and was collected under tree bark (Lent \& Wygodzinsky 1979), but has also been discovered (in all developmental stages) in peridomestic environments (De la Riva et al. 2001). Distribution: district of Paramaribo.

Rhodniini Pinto, 1926, R. pictipes Stål, 1872 - R. pictipes is a widespread silvatic species that is frequently attracted to light and is known to enter houses on occasion (Lent \& Wygodzinsky 1979, Torres \& Cabrera 2010). It is the most common species collected in Suriname and was often collected in domestic habitats. Distribution: districts of Paramaribo, Commewijne, Wanica, Para (Mapane), Brokopondo (Sara Creek), Saramacca, Coronie, Marowijne (Galibi) and Sipaliwini (Benzdorp, Nieuw Aurora, Apoera, Coeroeni-island, Kaboeri Creek, Bakhuys, Kwamalasamutu).
R. robustus Larrousse, 1927 - Some of the $R$. robustus specimens from Suriname were initially thought to be $R$. prolixus, but mt-DNA sequence analysis of the Suriname specimens confirms them as "type 4" $R$. robustus [following the designation of Monteiro et al. (2003), which conforms to the estimated distribution of genotypes in Abad-Franch and Monteiro (2007)]. R. prolixus itself has not been found in Suriname. Distribution: districts of Saramacca, Brokopondo (Klaaskreek), Para (Republiek), Marowijne (Galibi) and Sipaliwini (Nieuw Aurora).

Triatomini Jeannel, 1919, E. mucronatus Stål, 1859 - E. mucronatus is a sylvatic species with little epidemiological significance (Lent \& Wygodzinsky 1979). It can be found in a variety of habitats, including dry and wet tropical forests (Cuba et al. 2002). The one specimen found by the NZCS was collected in a recreational room at Brownsberg Nature Park, an ecotourist site situated at $500 \mathrm{~m}$ above sea level in a humid tropical forest. Its role as a vector of Chagas disease is considered insignificant (Barrett 1991), but evidence of domestic capture exists (Torres \& Cabrera 2010). Distribution: districts of Paramaribo, Brokopondo (Brownsberg) and Para (Zanderij).

P. geniculatus (Latreille, 1811) - P. geniculatus is a frequently encountered species in Suriname and is believed to have been the vector responsible for the first acute case of Chagas disease recorded in the country (Oostburg et al. 2003). Adults of this species are commonly attracted to light and encountered in peridomestic environments (Lent \& Wygodzinsky 1979, Torres \& Cabrera 2010). The species is thought to have the potential for domestication and was found breeding in pigsties near human dwellings in Brazil (Valente 1999). Most specimens from Suriname were collected in (peri)domestic surroundings. Distribution: districts of Paramaribo, Commewijne, Wanica, Para (Mapane), Saramacca and Sipaliwini (Nieuw Aurora, Sipaliwini savannah).

P. lignarius (Walker, 1873) - The one specimen of $P$. lignarius found by the NZCS came from a peridomestic situation, again most likely attracted by an electric light. This species was originally described by Walker, in 1873, but was then redescribed by Lent (1943) based on a Surinamese specimen provided by DC Geijskes, a Dutch entomologist. Distribution: districts of Wanica and Sipaliwini (Bakhuys).

P. mitarakaensis Bérenger and Blanchet, 2007 - P. mitarakaensis was described as a new species by Bérenger and Blanchet (2007) based on a specimen collected from a locality in the southeast of the Mitaraka Mountains (TumakHumak Mountain Range at the border with Brazil), which is part of the southern border of Suriname with French Guiana. Distribution: district of Sipaliwini [TumacHukac (Mitaraka Mountains)].

P. rufotuberculatus (Champion, 1899) - P. rufotuberculatus is also frequently attracted to electric light (Lent \& Wygodnzinsky 1979, Salomón et al. 1999). It is known mainly from low, dry areas, but may also be found in zones of humid premontane forests (Abad-Franch et al. 2001). The species has been found in domestic environments elsewhere (Torres \& Cabrera 2010). As originally 
described by Champion (1899), P. rufotuberculatus shows considerable morphological variation. The specimens encountered in Suriname have a reddish connexivum with a rectangular dark spot in each segment, slightly biconcave and a thin black band close to the intersegmental suture. The reddish carinae, limiting the central depression of the scutellum, appear to be similar to those found in specimens from Panama and Colombia [as described by Salomón et al. (1999)] and distinct from specimens from Costa Rica, Venezuela, Peru, Bolivia and Brazil, which generally present the scutellum entirely black. All post-colonial specimens originate from one residence in the district of Wanica. Distribution: districts of Paramaribo and Wanica.

T. maculata (Erichson, 1848) - One specimen of $T$. maculata was reportedly captured in Paramaribo. This was in 1963, when the capital had greater abundance of vegetation, including palm trees. No specimens have since been collected. T. maculata is a species with sylvatic and (peri) domestic occurrences (Luitgards et al. 2005, ReyesLugo et al. 2011). Considering that the species is not commonly found in a humid coastal habitat, the record needs confirmation . Distribution: district of Paramaribo.

\section{ACKNOWLEDGEMENTS}

To the NHML and the NZCS, for sharing of information, to my colleagues and friends A van Sauers-Muller and A Gangadin, for collecting Triatominae in their free time, to Dr F Monteiro, who carried out DNA sequencing of $R$. robustus specimens from Suriname, to Drs L Resida and Dr CJ Schofield, for reviewing an earlier version of the paper, and to the two anonymous reviewers who's remarks helped to improve the paper.

\section{REFERENCES}

Abad-Franch F, Ferraz G, Palomeque FS, Grijalva MJ, Aquilar HM, Miles MA 2010. Modeling disease vector occurrence when detection is imperfect: infestation of Amazonian palm trees by triatomine bugs at three spatial scales. PLoS Negl Trop Dis 4: 1-11.

Abad-Franch F, Monteiro FA 2007. Biogeography and evolution of Amazonian triatomines (Heteroptera: Reduviidae): implications for Chagas disease surveillance in humid forest ecoregions. Mem Inst Oswaldo Cruz 102 (Suppl. I): 57-69.

Abad-Franch F, Noireau F, Paucar AC, Aguilar HMV, Carpio CC, Racines JV 2000. The use of live-bait traps for the study of sylvatic Rhodnius populations (Hemiptera: Reduviidae) in palm trees. Trans R Soc Trop Med Hyg 94: 629-630.

Abad-Franch F, Palomeque FS, Aguilar HM, Miles MA 2005. Field ecology of sylvatic Rhodnius populations (Heteroptera, Triatominae): risk factors for palm tree infestation in western Ecuador. Trop Med Int Health 10: 1258-1266.

Abad-Franch F, Paucar CA, Carpio CC, Cuba CAC, Aguilar VHM, Miles MA 2001. Biogeography of Triatominae (Hemiptera: Reduviidae) in Ecuador: implications for the design of control strategies. Mem Inst Oswaldo Cruz 96: 611-620.

Aznar C, La Ruche G, Laventure S, Carme B, Liegeard P, Hontebeyrie M 2004. Seroprevalence of Trypanosoma cruzi in French Guiana. Mem Inst Oswaldo Cruz 99: 805-808.

Barrett TV 1991. Advances in triatomine bug ecology in relation to Chagas disease. Adv Dis Vector Res 8: 143-176.
Bérenger J-M, Blanchet D 2007. A new species of the genus Panstrongylus from French Guiana (Heteroptera: Reduviidae: Triatominae). Mem Inst Oswaldo Cruz 102: 733-736.

Bérenger J-M, Pluot-Sigwalt D, Pagès F, Blanchet D, Aznar C 2009. The Triatominae species of French Guiana (Heteroptera: Reduviidae). Mem Inst Oswaldo Cruz 104: 1111-1116.

Braga MV, Pinto ZT, Lima MM 1998. Life cycle and reproductive patterns of Triatoma rubrofasciata (De Geer, 1773) (Hemiptera: Reduviidae) under laboratory conditions. Mem Inst Oswaldo Cruz 93: 539-542.

Carcavallo RU, de Casas SIC, Sherlock IA, Galíndez IG, Jurberg J, Galvão C, Segura CAM, Noireau F 1999. Geographical distribution and alti-latitudinal dispersion. In RU Carcavallo, IG Girón, J Jurberg, H Lent (orgs.), Atlas dos vetores da doença de Chagas nas Américas, Vol. 3, Fiocruz, Rio de Janeiro, p. 747-792.

Castro MCM, Barrett TV, Santos WS, Abad-Franch F, Rafael JA 2010. Attraction of Chagas disease vectors (Triatominae) to artificial light sources in the canopy of primary Amazon rainforest. Mem Inst Oswaldo Cruz 105: 1061-1064.

Cuba CAC, Abad-Franch F, Rodríguez JR, Vásquez FV, Velásquez LP, Miles MA 2002. The triatomines of northern Peru, with emphasis on the ecology and infection by trypanosomes of Rhodnius ecuadoriensis (Triatominae). Mem Inst Oswaldo Cruz 97: 175-183.

De la Riva J, Matias A, Torrez M, Martínez E, Dujardin JP 2001. Adult and nymphs of Microtriatoma trinidadensis (Lent, 1951) (Hemiptera: Reduviidae) caught from peridomestic environment in Bolivia. Mem Inst Oswaldo Cruz 96: 889-894.

Gurgel-Gonçalves R, Galvão C, Costa J, Peterson AT 2012. Geographic distribution of Chagas disease vectors in Brazil based on ecological niche modeling. J Trop Med 2012: 1-15.

Harry M 1993a. Use of the median process of the pygophore in the identification of Rhodnius nasutus, $R$. neglectus, $R$. prolixus and R. robustus (Hemiptera: Reduviidae). Ann Trop Med Parasitol 87: 277-282.

Harry M 1993b. Isozymic data question the specific status of some blood-sucking bugs of the genus Rhodnius, vectors of Chagas disease. Trans R Soc Trop Med Hyg 87: 492.

Lent H 1943. Triatomídeos da Guiana Holandesa. Redescricão de Panstrongylus lignarius (Walker, 1873). Mem Inst Oswaldo Cruz 38: 485-496.

Lent H, Wygodzinsky P 1979. Revision of the Triatominae (Hemiptera: Reduviidae) and their significance as vectors of Chagas disease. Bull Am Mus Nat Hist 163: 123-520.

Luitgards-Moura JF, Vargas AB, Almeida CE, Magno-Esperança G, Agapito-Souze R, Folly-Ramos E, Costa J, Tsouris P, RosaFreitas MG 2005. A Triatoma maculata (Hemiptera, Reduviidae, Triatominae) population from Roraima, Amazon Region, Brazil, has some bionomic characteristics of a potential Chagas disease vector. Rev Inst Med Trop Sao Paulo 47: 131-137.

Luquetti A, Schofield CJ 2004. Chagas disease in the Guyanas. Proceedings of the ECLAT-AMCHA International Workshop on Chagas disease surveillance in the Amazon Region, Palmari, Brasil, Universidad de Los Andes, Bogota, p. 35-37.

Miles MA, Souza AA, Povoa M 1981. Chagas disease in the Amazon Basin. III. Ecotopes of ten triatomine bug species (Hemiptera: Reduviidae) from the vicinity of Belém, Pará state, Brazil. J Med Entomol 18: 255-278.

Monteiro FA, Barrett TV, Fitzpatrick S, Cordon-Rosales C, Feliciangeli D, Beard CB 2003. Molecular phylogeography of the Amazonian Chagas disease vectors Rhodnius prolixus and R. robustus. Mol Ecol 12: 997-1006. 
Nóbrega AA, Garcia MH, Tatto E, Obara MT, Costa E, Sobel J, Araújo WN 2009. Oral transmission of Chagas disease by consumption of açai palm fruit, Brazil. Emerg Infect Dis 15: 653-655.

Oostburg BFJ, Anijs JE, Oehlers GP, Hiwat H, Burke-Hermelijn SM 2003. Case report: the first parasitologically confirmed autochthonous case of acute Chagas disease in Suriname. Trans $R$ Soc Trop Med Hyg 97: 166-167.

PAHO - Pan American Health Organization 2009. Guyana Country Cooperation Strategy 2010-2015, Pan American Health Organization. Region office of the World Health Organizaiton (WHO). Available from: who.int/countryfocus/cooperation_strategy/ccs_guy_en.pdf.

Pavan MG, Monteiro FA 2007. A multiplex PCR essay that separates Rhodnius prolixus from members of the Rhodnius robustus cryptic species complex (Hemiptera: Reduviidae). Trop Med Int Health 12: 751-758.

Rawlings S, Baboolal S, Parsad K, Charles W, Tiwari T, Hardy L, Tjon A, Loi M, Oostburg BFJ 2001. The prevalence of antibodies to Trypanosoma cruzi in Guyana, Suriname and Trinidad and Tobago. Suriname Medical Bulletin 16: 25-40.

Reyes-Lugo M, Reyes-Contreras M, Salvi I, Gelves W, Avilán A, Llavaneras D, Navarrete LF, Cordero G, Sánchez EE, RodríguezAcosta A 2011. The association of Triatoma maculata (Ericsson 1848) with the gecko Thecadactylus rapicauda (Houttuyn 1782) (Reptilia: Squamata: Gekkonidae): a strategy of domiciliation of the Chagas disease peridomestic vector in Venezuela? Asian Pac J Trop Biomed 1: 279-284.
Roque AL, Xavier SC, da Rocha MG, Duarte AC, D’Andrea PS, Jansen AM 2008. Trypanosoma cruzi transmission cycle among wild and domestic mammals in three areas of oral transmitted Chagas disease outbreaks. Am J Trop Med Hyg 79: 742-749.

Salamanca-Dejour D, Blanchet D, Aznar C, La Ruche G, Jeannel D, Gastellu-Etchegorry M 2012. Chagas disease (American trypanosomiasis) in France. Med Mal Infect 42: 344-348.

Salomón OD, Ripoll CM, Rivetti E, Carcavallo RU 1999. Presence of Panstrongylus rufotuberculatus (Champion, 1899) (Hemiptera: Reduviidae: Triatominae) in Argentina. Mem Inst Oswaldo Cruz 94: 285-288.

Solís-Franco RR, Romo-Zapata JA, Martínez-lbarra JA 1997. Wild reservoirs infected by Trypanosoma cruzi in the ecological park "El Zapotal", Tuxtla Gutiérrez, Chiapas, México. Mem Inst Oswaldo Cruz 92: 163-164.

Torres DB, Cabrera R 2010. Geographical distribution and intra-domiciliary capture of sylvatic triatomines in La Convención province, Cusco, Peru. Rev Inst Med Trop Sao Paulo 52: 157-160.

Valente SAS, Valente VC, Pinto AYN, César MJB, dos Santos MP, Miranda COS, Cuervo P, Fernandes O 2009. Analysis of an acute Chagas disease outbreak in the Brazilian Amazon: human cases, triatomines, reservoir mammals and parasites. Trans $R$ Soc Trop Med Hyg 103: 291-297.

Valente VC 1999. Potential for domestication of Panstrongylus geniculatus (Latreille, 1811) (Liemiptera, Reduviidae, Triatominae) in the municipality of Muaná, Marajó Island, state of Pará, Brazil. Mem Inst Oswaldo Cruz 94 (Suppl. I): 399-400. 